\title{
Protective Film Formation on AA2024-T3 Aluminum Alloy by Leaching of Lithium Carbonate from an Organic Coating
}

\author{
Yanwen Liu, ${ }^{\mathrm{a}, \mathrm{z}}$ Peter Visser, ${ }^{\mathrm{b}, \mathrm{c}}$ Xiaorong Zhou, ${ }^{\mathrm{a}}$ Stuart B. Lyon, ${ }^{\mathrm{a}, *}$ Teruo Hashimoto, \\ Michele Curioni, ${ }^{a, *}$ Ali Gholinia, ${ }^{a}$ George E. Thompson, ${ }^{a, * *}$ Gerard Smyth, ${ }^{d}$ \\ Simon R. Gibbon, ${ }^{\mathrm{d}}$ Derek Graham, ${ }^{\mathrm{d}}$ Johannes M. C. Mol, ${ }^{\mathrm{b}}$ and Herman Terryn ${ }^{\mathrm{b}, \mathrm{e}, *}$ \\ ${ }^{a}$ School of Materials, The University of Manchester, Manchester M13 9PL, United Kingdom \\ ${ }^{b}$ Delft University of Technology, Department of Materials Science and Engineering, Delft, The Netherlands \\ ${ }^{c}$ AkzoNobel, Specialty Coatings, Research Development \& Innovation, Sassenheim, The Netherlands \\ ${ }^{d}$ AkzoNobel Research Development \& Innovation, Felling, United Kingdom \\ ${ }^{e}$ Vrije Universiteit Brussel, Group of Electrochemistry and Surface Engineering, Brussels, Belgium
}

\begin{abstract}
An investigation into corrosion inhibition properties of a primer coating containing lithium carbonate as corrosion inhibitive pigment for AA2024 aluminum alloy was conducted. It was found that, during neutral salt spray exposure, a protective film of about 0.2 to $1.5 \mu \mathrm{m}$ thickness formed within the area where an artificial defect was introduced by scribing through the coating to the base alloy. This film showed a multilayered structure consisting of a relatively compact layer near the alloy substrate, a porous middle layer and a columnar outer layer. The thicknesses of the layers varied, as a consequence of the difference in the local concentration of lithium species leaching from the primer coating. The presence of the film in the scribed area significantly reduced corrosion of the alloy, with little consumption of the metal substrate within the scribed area during neutral salt spray exposure. Furthermore, the presence of the protective film resulted in a significant increase of impedance modulus, measured after the salt spray exposure.

(C) The Author(s) 2015. Published by ECS. This is an open access article distributed under the terms of the Creative Commons Attribution 4.0 License (CC BY, http://creativecommons.org/licenses/by/4.0/), which permits unrestricted reuse of the work in any medium, provided the original work is properly cited. [DOI: 10.1149/2.0021603jes] All rights reserved.
\end{abstract}

Manuscript submitted September 8, 2015; revised manuscript received November 25, 2015. Published December 9, 2015.

The corrosion protection of aluminum alloys is critical for their successful application in the aerospace industry. Typically, several steps are employed to protect the alloy: surface cleaning and deoxidizing, ${ }^{1}$ conversion coating ${ }^{2,3}$ or anodizing, ${ }^{4}$ organic primer coating and decorative top coating. ${ }^{5-7}$ Cleaning and deoxidizing remove debris, lubricants, and near-surface deformed layers. The subsequent conversion coating or anodizing forms an extended oxide layer. The organic coatings control the access of the external environment to the underlying alloy and contain relevant functional components usually in the form of pigments. Where the coating is locally damaged, corrosion inhibitors, which are added into the organic primer as pigments, leach into the aqueous phase and react with the exposed alloy to form a protective film. Traditionally, strontium chromate is widely used as the corrosion inhibitive pigment in the organic primer for aerospace applications and has demonstrated to be very effective..$^{5-8}$ However, chromium (VI) species have toxic effects on kidneys, liver and blood in addition to carcinogenic effects ${ }^{9,10}$ and their use for corrosion protection applications must be limited or avoided, by finding suitable alternatives.

In order to develop suitable "green" active corrosion inhibitors, numerous research activities have been carried out since 1980s. Some of the most promising results were obtained with metal salts containing oxoanionic, e.g. molybdates, ${ }^{11-13}$ silicates, ${ }^{14}$ metavanadate, ${ }^{15-17}$ permanganate, ${ }^{18,19}$ phosphates, ${ }^{19-24}$ borate ${ }^{25,26}$ and tungstate. ${ }^{16}$ Rare earth $^{27-35}$ and other cation compounds ${ }^{11,13,20,27-35}$ were also found to be effective. Organic coatings containing ion exchange inhibitors, ${ }^{36,37}$ metals, ${ }^{16,38-41}$ and organic inhibitive compounds ${ }^{42-46}$ were also found to increase corrosion resistance of metals.

In 1987, lithium containing aluminum alloys were developed for use in aerospace applications; this trigged the need to study the role of the lithium cations when present in a salt solution. ${ }^{47}$ It was found that a passive region become evident during anodic polarization of aluminum alloy 6061-T6 in $0.05 \mathrm{M} \mathrm{Li}_{2} \mathrm{CO}_{3}$ solution. Such passive region was not present when $\mathrm{Li}_{2} \mathrm{CO}_{3}$ was replaced by $\mathrm{Na}_{2} \mathrm{CO}_{3}$ or $\mathrm{K}_{2} \mathrm{CO}_{3} \cdot{ }^{47}$ Lithium-based conversion coatings were developed in early $1990 \mathrm{~s},{ }^{48-51}$ using various lithium salts in alkaline solutions. Lithium cations were found to be intercalated into aluminum hydroxide to form insoluble layered double hydroxides. ${ }^{47-51}$ The protective proper-

\footnotetext{
*Electrochemical Society Active Member

**Electrochemical Society Fellow.

${ }^{\text {z} E-m a i l: ~ Y a n w e n . L i u @ m a n c h e s t e r . a c . u k ~}$
}

ties provided by these lithium conversion layers are thought to originate from the formation of a lithium-aluminum hydroxide-carbonatehydrate $\left(\mathrm{Li}_{2}\left[\mathrm{Al}_{2}(\mathrm{OH})_{6}\right]_{2} \cdot \mathrm{CO}_{3} \cdot \mathrm{nH} 2 \mathrm{O}\right)$ layer, ${ }^{48,49}$ which greatly increases the corrosion resistance of various substrates, by increasing the pitting potential and reducing the corrosion current density. ${ }^{47-51}$

Although many approaches have been attempted to achieve acceptable alternatives, few systems have achieved the effectiveness of chromate-containing systems. ${ }^{39,46}$ A potential replacement for the chromate-containing pigments in organic coatings using lithium salts has been developed recently. ${ }^{52,53}$ Neutral salt spray testing (ASTM B-117) revealed that when such pigments are added into organic coatings, the corrosion resistance increases, resulting in comparable behavior to chromate pigments. In a previous study, ${ }^{53}$ the general filming behavior of the film formed on damaged area of AA2024 aluminum alloy coated with a lithium carbonate and lithium oxalate pigmented coating was investigated. It was found that lithium ions were able to leach from the organic coating, forming a film in the damaged area of the coated alloy. This film provided effective corrosion protection and comprised multiple layers, exhibiting barrier, porous and columnar morphologies.

In the present study, the evolution of such a film in the damaged area of AA2024 aluminum alloy coated with a lithium carbonate pigmented coating was investigated. It was found that the films formed in the damaged area are able to effectively protect AA2024 aluminum alloy from corrosion during neutral salt spray exposure and have varied morphologies in different locations. The mechanisms of film formation were investigated using advanced microscopic techniques and electrochemical impedance spectroscopy.

\section{Experimental}

Analytic grade purity lithium carbonate, from Sigma Aldrich was used as the corrosion inhibitive pigment, which was formulated into a model organic coating. The weights and sources of individual organic and inorganic compounds used in the coating are listed in Table I. The pigment volume concentration (PVC) of lithium carbonate was $15 \mathrm{v} . \%$. The pigmented coatings were prepared according to the following procedure:

The individual components, including polyurethane polyol building block (Desmophen MPA), N-Butylacetate solvent, lithium carbonate, magnesium oxide, titanium dioxide and barium sulfate, used for Component A were added sequentially into a $370 \mathrm{ml}$ glass jar 
Table I. Composition of the model organic coating. ${ }^{53}$

\begin{tabular}{lll} 
& Supplier & Amount $(\mathrm{g})$ \\
\hline Component A & & \\
N-Butylacetate & Sigma Aldrich & 75.0 \\
Desmophen 650MPA & Bayer Materials science & 47.7 \\
Lithium carbonate & Sigma Aldrich & 23.6 \\
Magnesium oxide & Sigma Aldrich & 16.4 \\
TiOxide TR 92 & Huntsman & 5.9 \\
Blanc Fixe N (Ba( $\left(\mathrm{SO}_{4}\right)$ & Sachtleben & 15.4 \\
Component B & & \\
Tolonate HDB 75 MX & Vencorex & 28.5 \\
Dynasilan Glymo & Evonik & 5.2
\end{tabular}

with stirring, before 400 grams of Zirconox pearls (1.7-2.4 mm) were added to the mixture to aid dispersion. The mixture was then shaken for 20 minutes on a Skandex paint shaker to achieve a dispersed pigment particle size smaller than $25 \mu \mathrm{m}$. The Zirconox pearls were filtered after shaking. Component B that consists of polyisocyanates cross-linking agents (Tolonate HDB75MX) and an organosilane (Dynasilan Glymo) was mixed separately and then added to Component A. Finally, the mixture was stirred to a homogeneous state.

AA2024 aluminum alloy was anodized in tartaric-sulfuric acid according to aerospace requirements (AIPI 02-01-003) at Premium AEROTEC, Bremen, Germany. The primer coatings were applied to the anodized AA2024-T3 alloy with a HVLP (high-volume lowpressure) spray gun. The coated alloy panels were then cured at $80^{\circ} \mathrm{C}$ for 16 hours. The thicknesses of the coating after curing were between 20 and $25 \mu \mathrm{m}$.

A mechanical milling device was used to artificially damage the organic coating on AA2024 aluminum alloy with a U-shaped scribe. The coated panels, with dimensions of $7 \times 7 \mathrm{~cm}$, were scribed from corner to corner, leaving a $1 \mathrm{~mm}$ wide scribe that penetrated to a depth of 100-150 $\mu \mathrm{m}$ into the metal. After scribing, the samples were exposed to the neutral salt spray test (ASTM-B117) chamber, for varying periods of time $(4,8,24$, and $168 \mathrm{~h})$. After exposure, the samples were rinsed for $2 \mathrm{~min}$ with flowing deionized water to remove any residual chlorides and, subsequently, air dried.

After salt spray exposure for various times, the surface and cross sectional observation of the scribed area was carried out by scanning electron microscopy (SEM) using a ZEISS Ultra 55 instrument with an acceleration voltage of $0.5 \mathrm{kV}$. The cross sections of the scribed area were also examined by transmission electron microscopy (TEM) using a JEOL FX $2000 \mathrm{II}$ instrument operated at $120 \mathrm{kV}$. The electron transparent TEM foils, of nominal thickness of $15 \sim 50 \mathrm{~nm}$, were prepared using a Leica EM UC6 ultramicrotome with a diamond knife or by a focused ion beam technique with a FEI Quanta 3D SEM/FIB. High resolution TEM and electron energy loss spectroscopy (EELS) was conducted on a TECNAI F30 TEM fitted with a Gif 2001 detector, operated at $300 \mathrm{kV}$.

Apart from the electron microscopy, electrochemical impedance spectroscopy (EIS) was also employed to evaluate the protective behavior of the lithium carbonate pigmented organic coatings using a three-electrode cell with a working electrode of exposed area $12.56 \mathrm{~cm}^{2}$, a platinum counter electrode and a saturated calomel reference electrode (SCE). The testing cells were made by a cylindrical tube of $4 \mathrm{~cm}$ diameter, clamped to the testing samples with a rubber ring. Coated alloy samples with scribing before and after neutral salt spray exposure for $168 \mathrm{~h}$ were immersed in $0.05 \mathrm{M} \mathrm{NaCl}$ solution for $2 \mathrm{~h}$. Impedance measurements were taken at the free corrosion potential using an Autolab-PGSTAT30 computer-controlled potentiostat, with $10 \mathrm{mV}$ sine amplitude and a frequency range from $0.01 \mathrm{~Hz}$ to $3 \times 10^{4} \mathrm{~Hz}$.
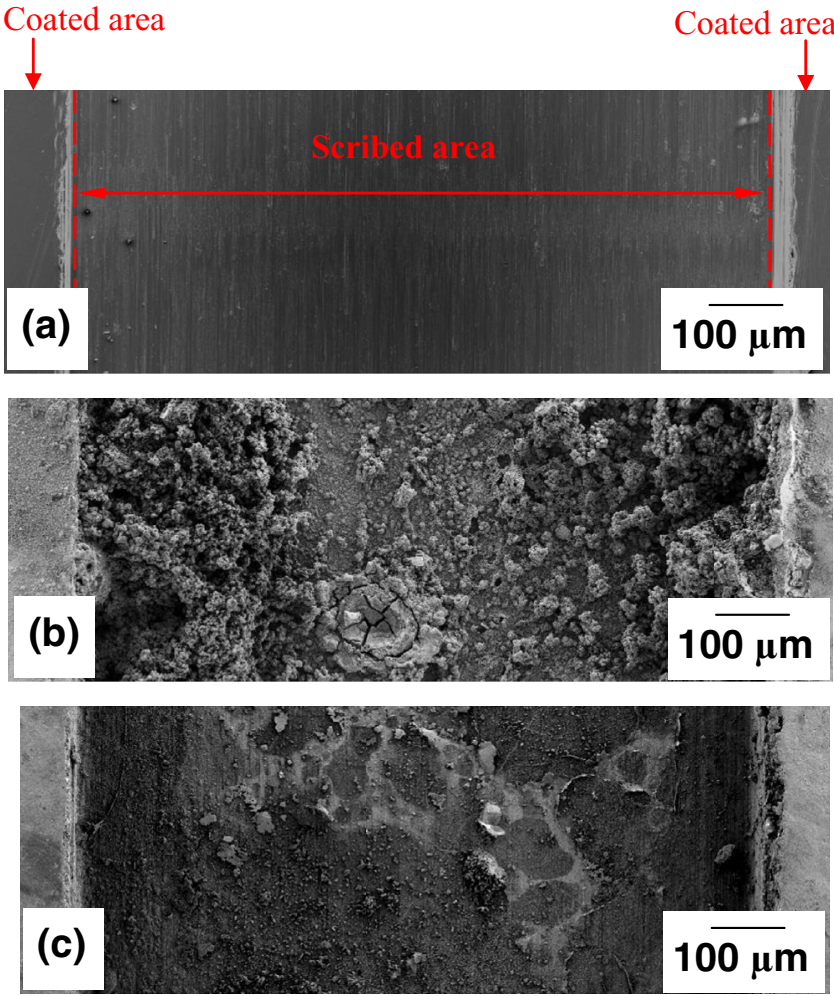

Figure 1. Scanning electron micrographs of the scribed area on AA2024-T3 before and after $168 \mathrm{~h}$ neutral salt spray exposure: (a) before; (b) after, with primer coating without lithium carbonate; and (c) after, with primer coating pigmented with lithium carbonate.

\section{Results}

Appearance of the scribed area before and after salt spray exposure.- Scanning electron micrographs of the scribed areas of the coated AA2024 aluminum alloy before and after salt spray exposure for $168 \mathrm{~h}$ are displayed in Fig. 1. The scribed areas of the alloy substrate, where the coatings were removed over a width of $1 \mathrm{~mm}$, are in the center with the coated alloy substrate evident on the left and right sides. After the exposure to neutral salt spray conditions, a significant amount of corrosion products was formed on the alloy with a non-inhibitive coating (Fig. 1b), suggesting severe corrosion within the scribed area. However, when lithium carbonate was added into the coating, the scribed area appeared much cleaner (Fig. 1c), indicating effective protection within the scribed area by the coating.

Fig. 2 shows the surface and cross sectional views of the scribed area before salt spray exposure, revealing a mixture of shingling, cracking, and parallel scribing lines, as well as metal debris, resulting from the high levels of shear strain imposed during the scribing process (Fig. 2a). Cross sectional examination of the shingling within the scribed area showed partial detachment of metal from the surface, suggesting delamination of surface/near-surface regions as a result of the scribing (Fig. 2b). Away from the shingled region, the surface was relatively flat, as shown by Fig. 2c, which displays the cross section of the framed region in Figure 2a. Fig. 3 shows the surface and cross sectional views of the scribed area after salt spray exposure for $168 \mathrm{~h}$. After $168 \mathrm{~h}$ salt spray exposure, for the primer coating without lithium carbonate, the initial scribe lines and shingles had disappeared. Instead, corrosion products were deposited on the surface (Fig. 3a). The corrosion products showed fine flake-shaped morphologies on the surface (Fig. 3b). Cross sectional examination (Fig. 3c-3e) of the area showed a thick layer of corrosion products, of about $25 \mu \mathrm{m}$ thickness, in the middle of the scribed area (Fig. 3c). The majority of the corroded area showed a smooth alloy/corrosion product interface, indicating that active alkaline corrosion was the predominant process. 

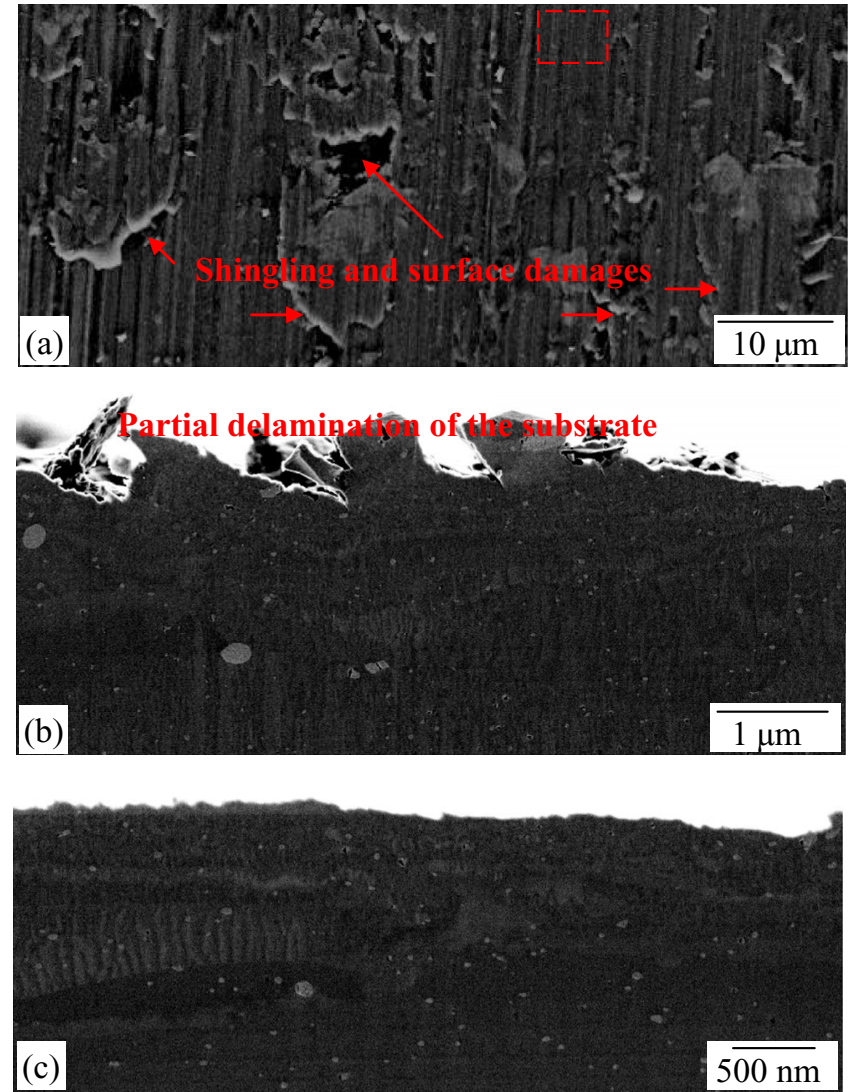

Figure 2. Scanning electron micrographs of the scribed area on AA2024-T3 aluminum alloy before neutral salt spray testing: (a) surface view; (b) and (c) cross sectional views of the near-surface region.

Pitting corrosion (Fig. 3d) and intergranular corrosion (Fig. 3e), associated with acidified environment at the corrosion front, ${ }^{54,55}$ were also observed locally in the cross sectional view.

After $168 \mathrm{~h}$ salt spray exposure, for the primer that was pigmented with lithium carbonate, the scribed area showed a different morphology to that of the non-inhibited coating. Although the original surface features were still visible, they appeared less prominent (Fig. 4a). The scribed area showed bright and dark regions when studied with SEM (Figs. 4a and 4b). Dark regions of about $140 \mu \mathrm{m}$ width were observed on the two sides close to the primer coating (Fig. 4a). In the center and near center region of the scribed area, the dark region was mixed with the bright region, with circular and irregular appearances (Fig. 4b). Figs. 4c and 4d show the regions A and B indicated in Fig. $4 \mathrm{~b}$, respectively, at increased magnification, revealing that the dark regions observed in Fig. $4 \mathrm{~b}$ are associated with the presence of columnar/petal morphologies, while the bright regions exhibit a relatively flat appearance. Isolated oval or irregular features with dimensions from 1 to $10 \mu \mathrm{m}$ (indicated by circles) were randomly observed on the surface (Fig. 4c). Cross sectional examination showed that the scribed area developed a thin film during the salt spray exposure (Figs. $4 \mathrm{e}-4 \mathrm{~h})$. The thickness of the film varied from 0.2 to $1.5 \mu \mathrm{m}$. Some regions of the film consisted of a dense barrier region close to the alloy/film interface, a porous region in the middle and a columnar/petal shaped region at the top (Fig. 4e, the left side in Fig 4f), while in other regions the columnar/petal region was insignificant (Figs. $4 \mathrm{~g}$ and $4 \mathrm{~h}$ ). For the location where a $\mathrm{CuAl}_{2}$ second phase particle was present, the thickness of the film was more than $4 \mu \mathrm{m}$ (Fig. $4 \mathrm{~g}$ ). A relatively flat film was formed in the center region of the scribed area (Fig. 4h), which correlates to the bright region on surface view. On the other hand, the film formed on an AlFeMnCu particle was similar to that formed on the adjacent matrix (Fig. 4h). Comparing the surface view with the cross sectional view, it is possible that the isolated oval
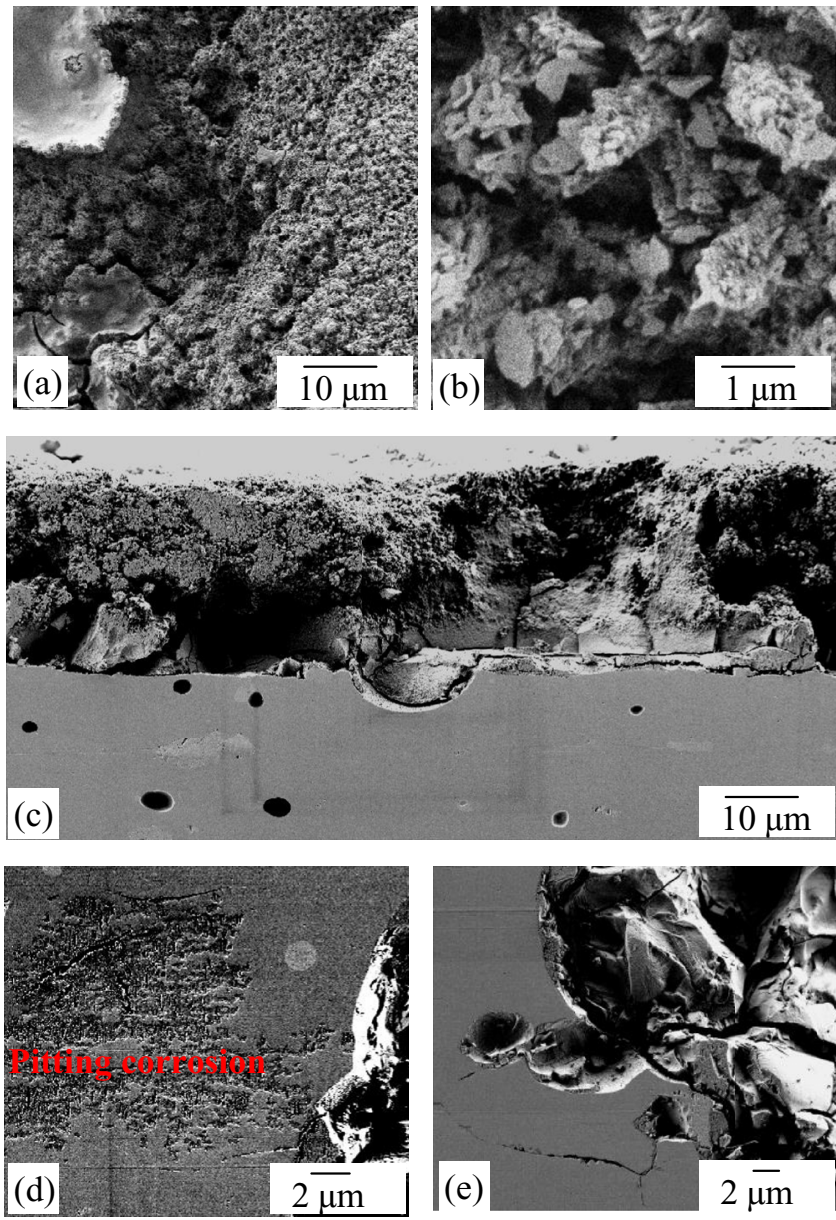

Figure 3. Scanning electron micrographs of surface (Figs. $3 a$ and $3 b$ ) and cross sectional (Figs. 3c-3e) views of the scribed area on AA2024-T3 aluminum alloy after neutral salt spray exposure for $168 \mathrm{~h}$ in the absence of lithium carbonate in the primer coating: (a) surface view of the scribed area, showing significant corrosion products; (b) The corrosion products with fine flake-shaped morphologies; (c) cross sectional view, revealing the thickness of corrosion products being about $25 \mu \mathrm{m}$ in the middle of scribed area; (d) cross sectional view showing pitting corrosion at local region; and (e) cross sectional view showing intergranular corrosion at local region.

or irregular features (as indicated by the dash-lined circles) observed in Fig. 4c are associated with the partial delamination of the alloy resulted from the mechanical scribing (Fig. 2b), or the presence of second phase particles beneath, as shown in Figs. $4 \mathrm{f}-4 \mathrm{~g}$.

Early stage of corrosion and filming behavior during salt spray exposure.- The early stage of the corrosion and filming behavior within the scribed area on the alloy with coatings in the absence and presence of the lithium carbonate during salt spray exposure for 4,8 , and $24 \mathrm{~h}$ were also examined.

Coating without lithium carbonate.-After salt spray exposure for $4 \mathrm{~h}$, localized corrosion was observed in the edge region of the scribed area, associated with a cluster of second phase particles. Away from the second phase particles, intergranular corrosion also developed deep into the metal substrate (Fig. 5a). In the center of the scribed area, corrosion products were evident across the surface. The thickness of the corrosion products was about $1-2 \mu \mathrm{m}$ over the alloy matrix. Pores and cracks were also observed in the corrosion products (Fig. 5b). The corrosion product with porosity provides little corrosion protection. After salt spray exposure for $8 \mathrm{~h}$ (Figs. $5 \mathrm{c}-5 \mathrm{e}$ ), corrosion products with similar features were observed (Fig. 5c). A dense barrier layer was formed closer to the alloy/corrosion products interface, with a layer 

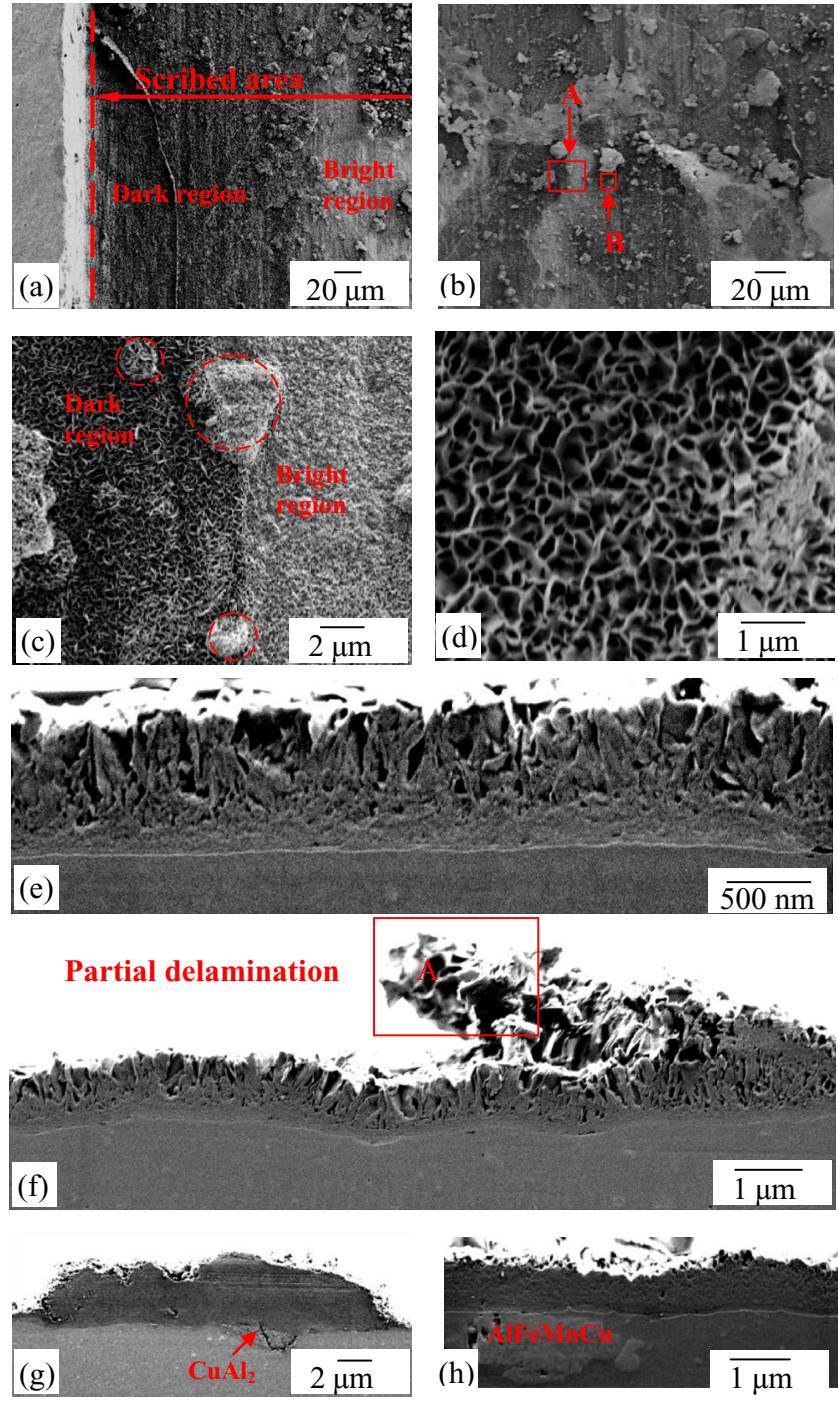

Figure 4. Scanning electron micrographs of the scribed area on AA2024-T3 aluminum alloy coated with the lithium carbonate pigmented coating after 168 h neutral salt spray: (a) region close to the coating, showing a relatively dark appearance compared to the middle region; (b) middle region of the scribed area, revealing a mixture of dark and bright appearance; (c) and (d) columnar/petal appearance in the region of dark appearance, relatively flat surface in the region of bright appearance; (e) cross sectional view of the scribed area, showing a film with three distinct layers, i.e. columnar/petal outer layer, porous layer in the middle and a barrier inner layer; (f) a protruded film related to the partial delamination of the alloy introduced by scribing; (g) film formed above a $\mathrm{CuAl}_{2}$ second phase particle; and (h) relatively flat film in the middle region of scribed area, correlating to the bright region on surface view. The film formed on an $\mathrm{AlFeMnCu}$ particle was similar to the adjacent matrix.

with porous morphology above the barrier layer (Fig. 5d). The barrier layer showed good adhesion to the alloy substrate, but displayed a significant number of cracks both within the layer (Fig. 5d) and at the alloy/corrosion product interface (Fig. 5c). Pitting corrosion was also observed locally (Fig. 5e). The thickness of the corrosion products was similar to that observed after $4 \mathrm{~h}$ salt spray testing.

After $24 \mathrm{~h}$ salt spray exposure (Figs. $5 \mathrm{f}-5 \mathrm{~g}$ ), the thickness of the corrosion products reached 5-30 $\mu \mathrm{m}$ (Fig. 5f). Further, significant pitting corrosion had developed locally, which was revealed on the left side of Fig 5f. Small and large cavities, ranging from 1 to $20 \mu \mathrm{m}$ (Figs. 5f, 5g), were observed in the area where pitting corrosion had developed (Figs. 5f, 5g).
Coating with lithium carbonate.-Cross sectional examination of the scribed area on the alloy with the lithium carbonate pigmented coating after salt spray exposure for 4,8 and $24 \mathrm{~h}$ is displayed in Figs. 6a-6i, showing that a protective film formed within a few hours of exposure. Interestingly, there is little evidence of corrosion after exposure for $24 \mathrm{~h}$. After $4 \mathrm{~h}$ exposure (Figs. 6a-6c), thin columnar layer has developed at the edge region of the scribed area (Fig. 6a). Furthermore, a porous outer layer and a dense inner barrier layer are evident near central region (Fig. 6b). The pores are larger at the outer region, showing a transition from porous to columnar/petal morphology. Barrier inner-layer with a thin porous outer layer was observed in the central region (Fig. 6c). After $8 \mathrm{~h}$ salt spray exposure, the film morphology is similar to that developed after $4 \mathrm{~h}$, but the film became thicker, as shown in Figs. 6d, 6e, and 6f. Significant columnar and porous layer were developed close to the edge region of the scribed area (Fig. 6d) while porous/barrier film was developed near the center of the scribed area (Fig. 6e). In the central region, mainly barrier-layered film was developed (Fig. 6f). After $24 \mathrm{~h}$ exposure, a film with a columnar/petal morphology and almost no barrier inner layer was revealed at edge region of the scribed area (Fig. $6 \mathrm{~g}$ ). Moving away from the edge region, a three-layered morphology with significant columnar layer was observed (Fig. 6h). Near center of the scribed area, film developed a barrier inner layer, with a thin porous and columnar outer layer (Fig. 6i).

The composition and structure of the protective film.- The ultramicrotomed cross sections of the scribed area of the AA2024 alloy coated with the primer without lithium carbonate pigment before and after salt spray exposure were examined by transmission electron microscopy (TEM). Before the salt spray exposure, it is evident that a near-surface deformed layer, approximately $0.8-1 \mu \mathrm{m}$ thick, with a sharp transition to the underlying, large grained, bulk alloy microstructure, was generated by the scribing (Fig. 7a). The deformed layer was observed previously when thermomechanical processing or mechanical polishing was carried out in aluminum alloys. ${ }^{56-60}$ The deformed layer microstructure is characterized by very fine grains, approximately $20-100 \mathrm{~nm}$ diameter (Fig. 7a). For the organic coating without lithium carbonate, after the salt spray exposure, the TEM image taken from the scribed area on the alloy shows a thin film at the alloy surface, with the majority of the corrosion products detached from the surface (Fig. 7b). The near-surface deformed layer is now absent from the alloy surface, indicating that corrosion completely consumed the near-surface deformed layer.

Fig. 8 displays TEM micrographs of the cross sections taken from the scribed area of the AA2024 alloy with lithium carbonate pigmented coating after salt spray exposure for $168 \mathrm{~h}$, revealing thin films formed on the alloy surface. The cross sections were prepared by ultramicrotomy (Figs. 8a-8b) and focused ion beam (Fig. 8c) in various locations of the scribed area. The thicknesses of the films formed during salt spray exposure ranged from 0.2 to $1.5 \mu \mathrm{m}$. Fig. 8a reveals a barrier film in the center of the scribed areas. A film with significant columnar/petal outer layer, porous middle layer and barrier inner layer was observed near the edge of the scribed area (Fig. 8b). Fig. 8c shows a TEM micrograph obtained from the area between the edge region and the center of the scribed area. Interestingly, beneath the thin film formed during neutral salt spray exposure, the near-surface deformed layer introduced by the scribing was still present, indicating that corrosion of the alloy substrate was very limited and a fast, effective inhibition mechanism had operated. At increased magnification, area A indicated in Fig. 8c exhibits the three layer morphology (Fig. 8d), with lithium distributed in these layers, as shown by the corresponding EELS map (Fig. 8e).

Fig. 9a captured the film formed on the partial delaminated alloy (as indicated by the frame in Figure 4f), which shows a barrier inner layer, surrounded by the porous and columnar/petal layers. The EELS elemental maps of the film are displayed in Fig. 9b-9d, revealing the presence of lithium, oxygen and aluminum.

Fig 10a shows a high-resolution TEM image of the film formed in the scribed area during salt spray exposure, revealing a mixture of 

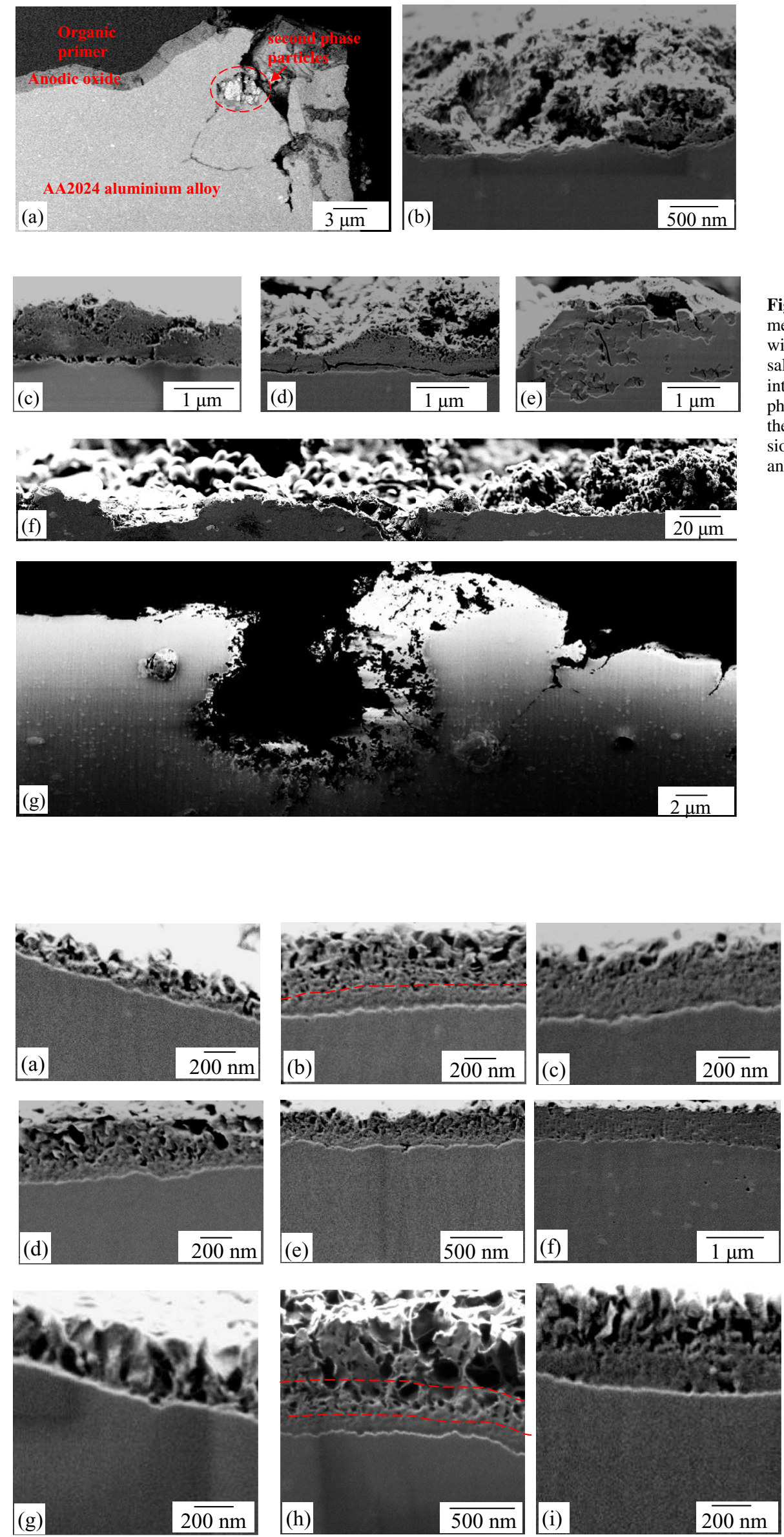

Figure 5. Cross sectional view of corrosion development in the scribed area on the AA2024 alloy coated with the primer without lithium carbonate after neutral salt spray exposure for 4,8 and $24 \mathrm{~h}$ : (a)-(b) $4 \mathrm{~h}$, revealing intergranular corrosion in the alloy matrix (a), and morphology of corrosion products (b); (c)-(e) $8 \mathrm{~h}$, revealing the similar featured corrosion products and pitting corrosion (e); (f)-(g) $24 \mathrm{~h}$, showing alkaline corrosion, pitting and intergranular corrosion.
Figure 6. Cross sectional view of protective film formed in the scribed area on the alloy coated with the lithium carbonate pigmented primer after salt spray exposure: (a)-(c) $4 \mathrm{~h}$; (d)-(f) $8 \mathrm{~h}$; (g)-(i) $24 \mathrm{~h}$. 

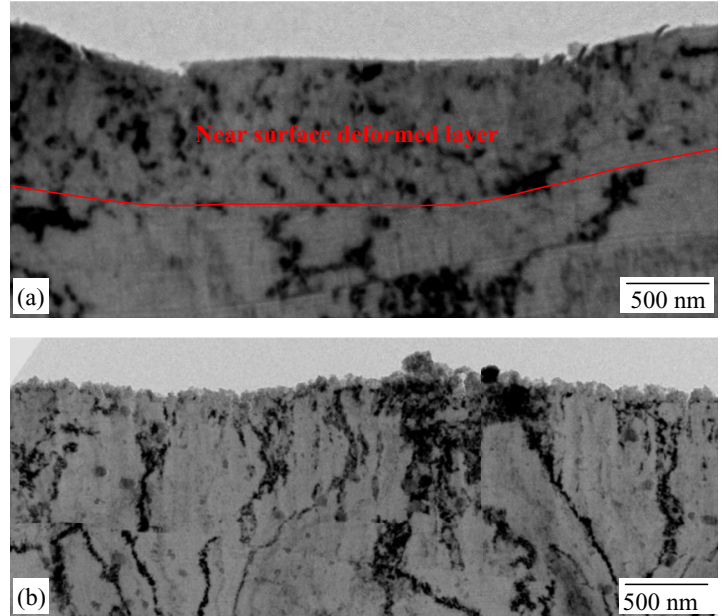

Figure 7. Transmission electron micrograph of the ultramicrotomed cross sections of the scribed area of the AA2024 alloy coated with organic coating without lithium carbonate pigment examined by transmission electron microscopy: (a) before exposure to the salt spray, the near surface region revealed a deformed layer; and (b) after exposure to salt spray for $168 \mathrm{~h}$, the deformed layer is absent. The samples were prepared by ultramicrotomy.

amorphous and nano-sized crystalline structures, as indicated by the dash-lined circles. Figs. 10b and 10c display two of the nano-crystals at increased magnification, exhibiting the lattice fringe images. The interplanar spacings and the angles between the planes measured from Figs. $10 \mathrm{~b}$ and $10 \mathrm{c}$ are presented in Tables II and III. Comparing the
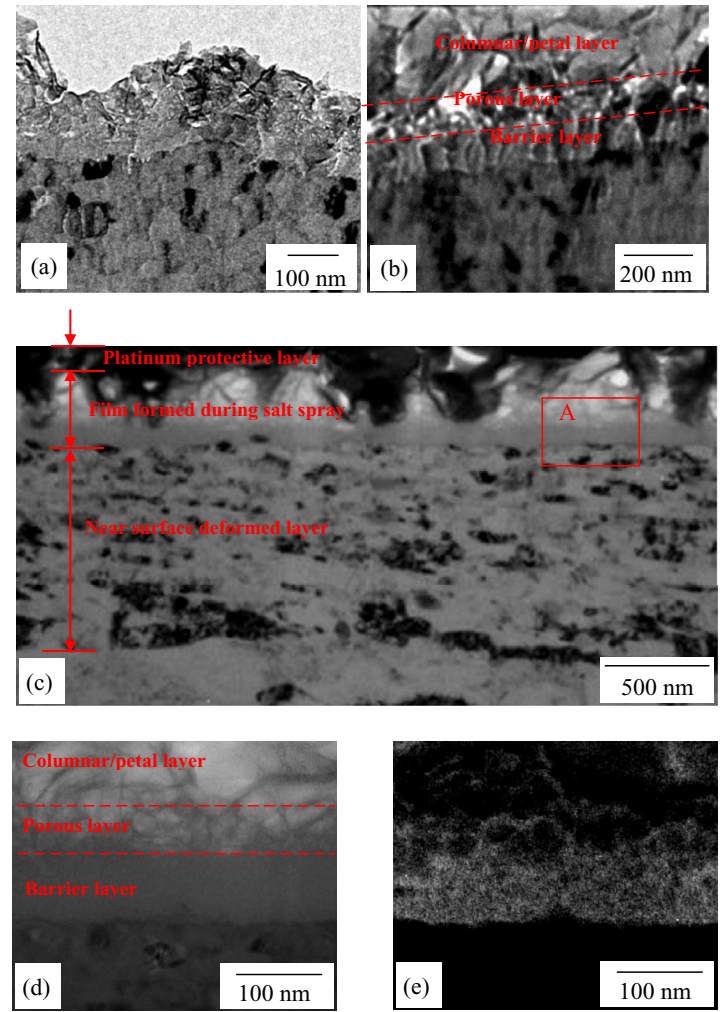

Figure 8. TEM cross sectional examination of the film formed in the scribed area of AA2024 alloy coated with lithium carbonate pigmented coating after $168 \mathrm{~h}$ salt spray exposure: (a) the film with barrier layer; (b) the film with the columnar/petal layer, porous layer and barrier layer; (c) the three layered film and the near surface deformed layer introduced by scribing; (d) area A indicated in (c) at increased magnification; (e) corresponding EELS map of (d), showing the presence of lithium in the film.
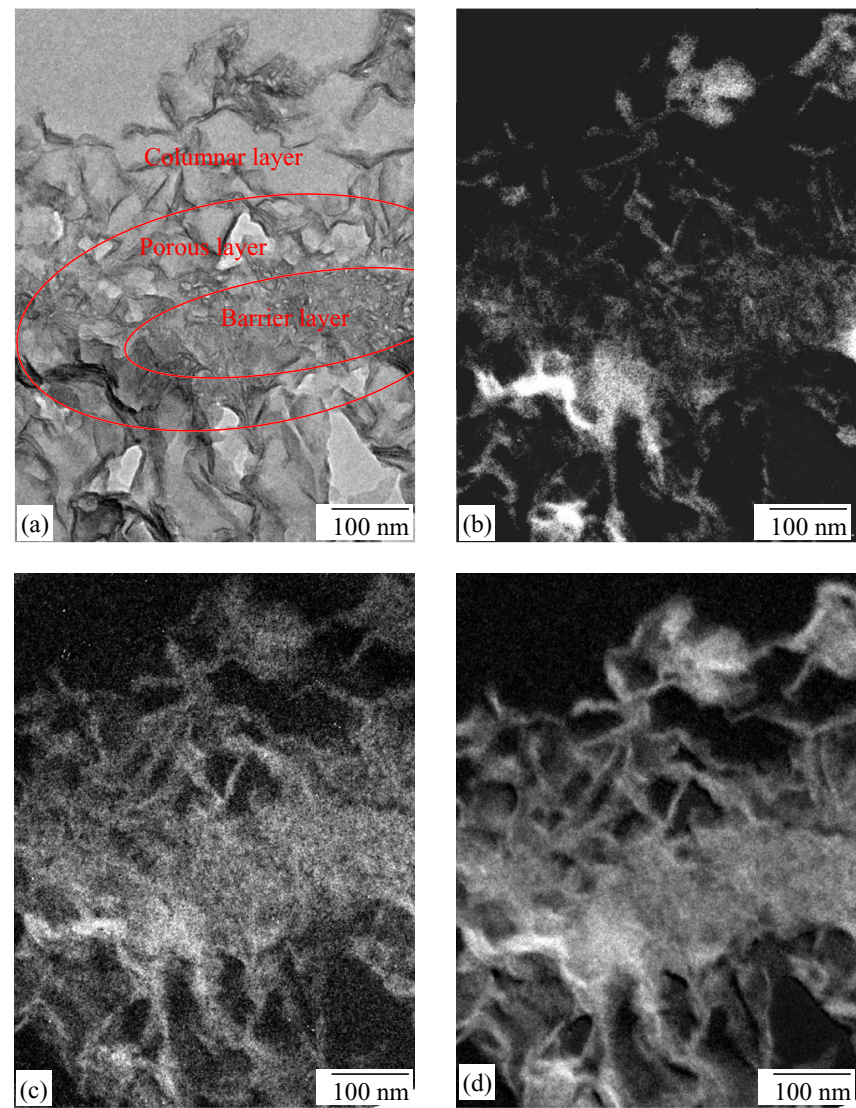

Figure 9. (a) Transmission electron micrograph of the film formed on the partial delaminated alloy, as indicated by the frame in Figure 4f; corresponding EELS elemental maps of the film: (b) lithium map; (c) aluminum map; and (d) oxygen map.

measured values from a number of the lattice fringe images obtained from the nano-crystalline regions with the lattice parameters of the possible crystal structures presented in Tables II and III, it was evident that the characterization of the crystal structure is not conclusive since the measured lattice parameters in this study could not distinguish between the lithium-aluminum-carbonate-hydroxide hydrate version of hydrotalcite, ${ }^{49,63} \alpha-\mathrm{LiAlO}_{2}{ }^{61,62}$ and $\mathrm{Al}(\mathrm{OH})_{3}{ }^{64,65}$

Electrochemical impedance spectroscopy.- The corrosion resistance of the film formed in the scribed area during salt spray exposure of the alloy coated with the lithium carbonate pigmented coating was evaluated by electrochemical impedance spectroscopy (EIS). The samples were immersed in $0.05 \mathrm{M} \mathrm{NaCl}$ before and after salt spray exposure; this represents the two conditions of the scribed area, i.e. with and without the thin film formed during the salt spray exposure. Further, a reference sample coated with the organic coating without lithium carbonate pigment was also evaluated by EIS after neutral salt spray exposure. From the bode plot of the impedance modulus (Figure 11a), it is evident that the lithium carbonate containing sample displays low-frequency impedance values that are about one order of magnitude higher than those measured from other two samples at low frequency, i.e. the lithium carbonate containing sample before salt spray exposure, and the reference sample coated with the coating without lithium carbonate pigment after salt spray exposure. The impedance modulus spectrum acquired for the specimen with lithiumcontaining pigments after salt spray exposure also displayed higher values of impedance in the medium frequency range, which is due to the formation of a protective film.

The Bode phase diagram (Figure 11b) of the sample with lithium carbonate pigmented coating before salt spray exposure shows clearly the time constant of the natural oxide film in the scribed area at the 

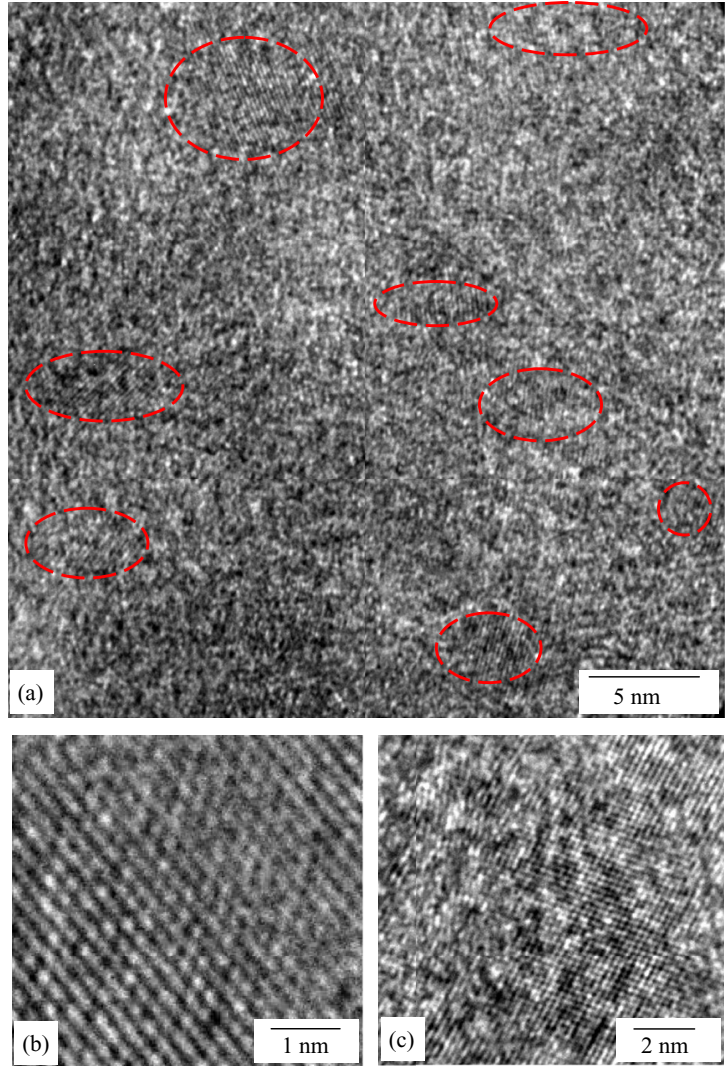

Figure 10. (a) TEM image of the film formed in the scribed area during salt spray exposure, revealing a mixture of amorphous and nano-sized crystalline structures; (b)-(c) lattice fringe images of the nano-crystals.

frequency at or above $\sim 10 \mathrm{~Hz}$. After salt spray exposure the sample shows an increase and broadening of the phase, again indicating that a thicker and stable film was formed in the scribed area during the exposure. On the other hand, for the sample coated with primer without lithium carbonate, a broad but lower phase range with lower impedance modulus was observed. These results confirm that the formation of the lithium containing film on the scribed area during the salt spray exposure resulted in an improvement of the corrosion re-
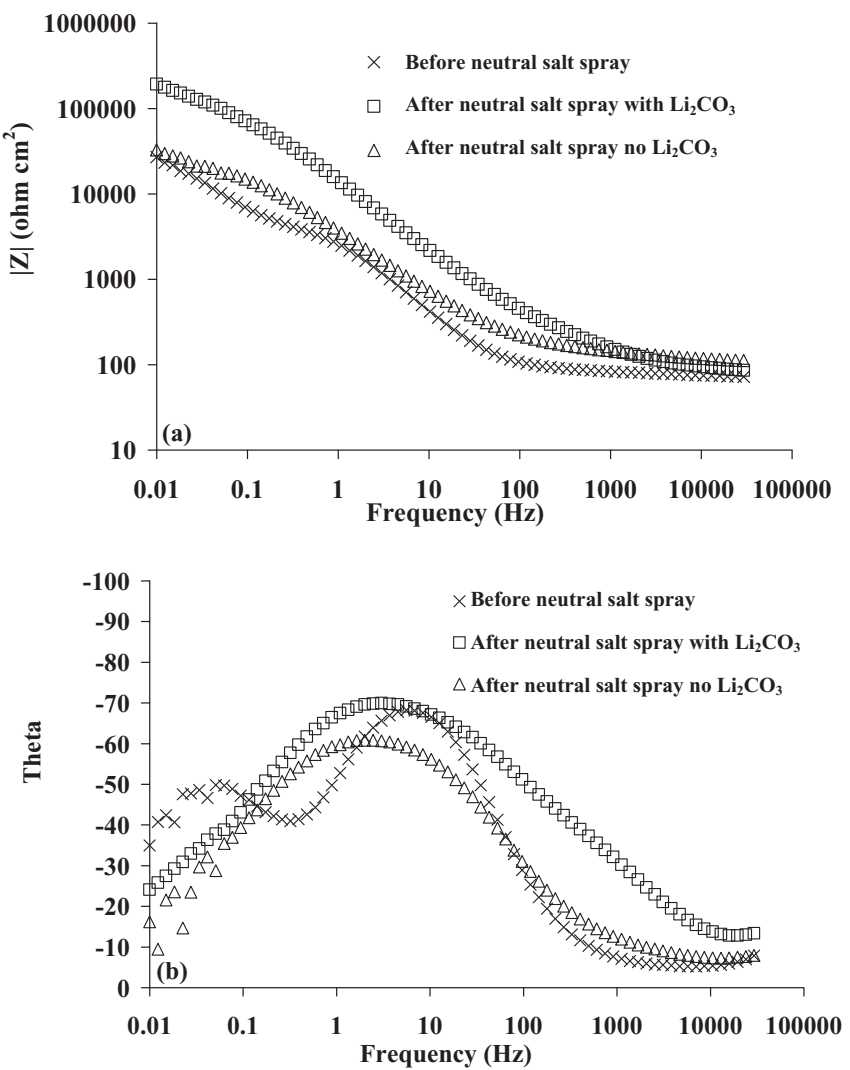

Figure 11. (a) Bode magnitude and (b) phase plots of electrochemical impedance spectra of the coated AA2024 aluminum alloy with a scribing in $0.05 \mathrm{M} \mathrm{NaCl}$ solution before and after salt spray exposure for $168 \mathrm{~h}$.

sistance, with a significant increase in the overall value of impedance compared to the reference samples.

\section{Discussion}

Direct observation and comparison of the scribed area on the coated AA2024 aluminum alloy before and after salt spray exposure for $168 \mathrm{~h}$ in Fig. 1 have revealed the significant role of lithium carbonate

Table II. Interplaner d-spacings measured from the lattice image in Figure 10b and the lattice parameters of the possible crystal structures.

\begin{tabular}{lcccccc} 
& Zone axis & Plane 1 & d-spacing $(\mathrm{nm})$ & Plane 2 & d-spacing $(\mathrm{nm})$ & Angle between the two planes $\left(^{\circ}\right)$ \\
\hline Measured values & & & $0.25 \pm 0.01$ & & $0.24 \pm 0.01$ & $61 \pm 1$ \\
$\mathrm{LiAl}_{2}(\mathrm{OH})_{7} \mathrm{H}_{2} \mathrm{O}$ (Hexagonal) & {$[1-11]$} & 110 & 0.255 & $2-1-3$ & 0.242 & 61.727 \\
$\mathrm{Li}_{2} \mathrm{Al}_{4} \mathrm{CO}_{3}(\mathrm{OH})_{12} 3 \mathrm{H}_{2} \mathrm{O}$ (Hexagonal) & {$\left[\begin{array}{lll}1-1 & 1\end{array}\right]$} & 110 & 0.255 & $2-1-3$ & 0.242 & 61.701 \\
$\mathrm{Li}_{2} \mathrm{Al}_{4} \mathrm{CO}_{3}(\mathrm{OH})_{12} 3 \mathrm{H}_{2} \mathrm{O}$ (monoclinic) & {$\left[\begin{array}{lll}1 & 0-3\end{array}\right]$} & 020 & 0.254 & $-31-1$ & 0.239 & 61.935 \\
$\mathrm{LiAlO}_{2}(\mathrm{Hexagonal})$ & {$[201]$} & 010 & 0.242 & $10-2$ & 0.229 & 61.763 \\
$\mathrm{Al}(\mathrm{OH})_{3}$ (monoclinic) & {$[10-3]$} & 020 & 0.254 & $-31-1$ & 0.239 & 61.935 \\
$\mathrm{Al}(\mathrm{OH})_{3}$ (hexagonal) & Not match & & & & &
\end{tabular}

Table III. Interplaner d-spacings measured from the lattice image in Figure 10c and the lattice parameters of the possible crystal structures.

Measured values

$\mathrm{LiAlO}_{2}$ (Hexagonal)

$\mathrm{LiAl}_{2}(\mathrm{OH})_{7} \mathrm{H}_{2} \mathrm{O}$ (Hexagonal)

$\mathrm{Li}_{2} \mathrm{Al}_{4} \mathrm{CO}_{3}(\mathrm{OH})_{12} 3 \mathrm{H}_{2} \mathrm{O}$ (Hexagonal)

$\mathrm{Li}_{2} \mathrm{Al}_{4} \mathrm{CO}_{3}(\mathrm{OH})_{12} 3 \mathrm{H}_{2} \mathrm{O}$ (monoclinic)

$\mathrm{Li}_{2} \mathrm{Al}_{4} \mathrm{CO}_{3}(\mathrm{OH})_{12} 3 \mathrm{H}_{2} \mathrm{O}$ (monoclinic)

$\mathrm{Al}(\mathrm{OH})_{3}$ (monoclinic)

$\mathrm{Al}(\mathrm{OH})_{3}$ (hexagonal)
Zone axis $\quad$ Plane $1 \quad$ d-spacing $(\mathrm{nm}) \quad$ Plane $2 \quad$ d-spacing $(\mathrm{nm}) \quad$ Angle between the two planes $\left(^{\circ}\right)$

$0.2 \pm 0.01$

$80 \pm 1$

Not match

[20-5 -2]

$0.20 \pm 0.01$

$[20-5-2] \quad 02-5$

0.198

$-10-10$

0.201

$0.198-10-10$

0.201

79.318

[-7 - $10-2] \quad 20-7$

0.198

$\left[\begin{array}{lll}3 & 0 & -2\end{array}\right]$

223

[-2 -9-1] $20-4$

0.201

$-22-3$

0.201

0.204

$\left[\begin{array}{lll}-5 & -1 & 2\end{array}\right]$

021
$-22-3$

$-31-3$

$1-12$

\subsection{1}

0.205

0.208
79.318

81.257

78.038

79.917

81.206 


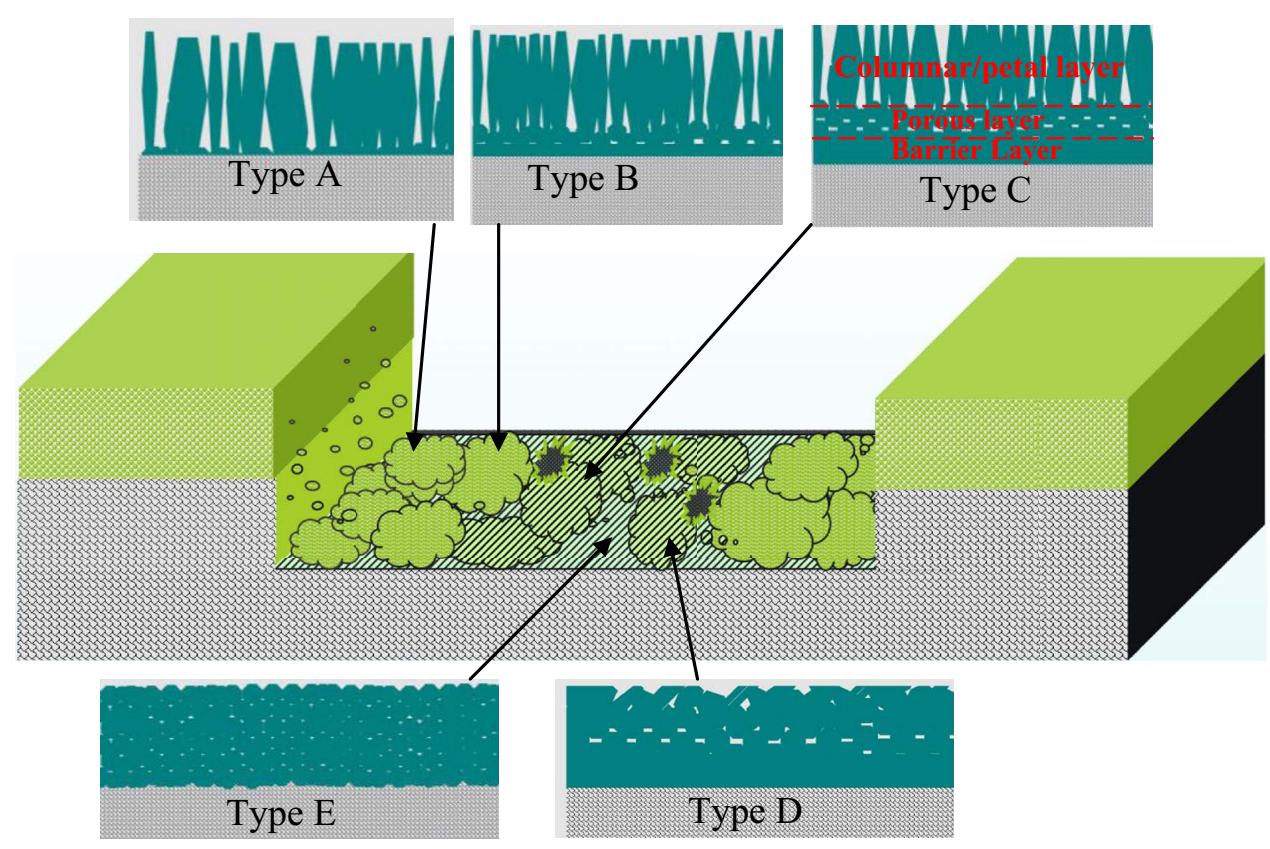

Figure 12. A schematic diagram illustrating the film morphologies observed at different locations within the scribed area of the alloy coated with lithium carbonate pigmented coating: Type A: columnar/petal layer with little barrier and porous layers; Type B: significant columnar/petal layer with porous and barrier layers; Type C: typical three layered morphology; Type D: porous and barrier layers; Type E: barrier layer.

as leachable inhibitor in the organic coating. This has led to a detailed investigation of the protection mechanism of the alloy by lithium carbonate as corrosion inhibitor, as discussed below.

Comparing Figs. 2a-2c with Figs. 3a-3e, it is evident that extensive corrosion had developed in the scribed area when lithium carbonate was absent, which changed the surface appearance in the scribed area and developed relatively thick corrosion products. Such products are mainly aluminum hydroxide. Such hydroxide showed low protective properties, as suggested by electrochemical impedance results. On the contrary, for the alloy coated with the lithium carbonate loaded coating, the scribed area showed little evidence of corrosion after the neutral salt spray exposure. Examination of this region revealed that a thin film, containing lithium, aluminum and oxygen, was formed on the alloy surface during the salt spray exposure. The presence of lithium species in the film indicates that lithium species are able to leach out from the primer coating to the scribed alloy surface and form a stable protective film that protects the alloy from subsequent corrosion. Furthermore, such films provide corrosion protection, as evident from EIS measurement after neutral salt spray exposure.

From the observation of the filming behavior after exposure to salt spray for $4,8,24$, and $168 \mathrm{~h}$, it is evident that the film formation commenced in the early stage of neutral salt spray exposure. With increasing exposure time, the film thickens with significant development of a columnar/petal layer on the outer region, which may be due to the increased lithium species available for the film formation. On the other hand, the film thickness was influenced by the local cathodic/anodic activities, especially the presence of cathodic $\mathrm{CuAl}_{2}$ particles.

The morphology of the protective film showed three distinct layers, containing a barrier layer close to the alloy interface, a porous central layer, and a columnar/petal outer layer. However, the relative thickness of the three layers varied. Some regions developed a significant barrier layer while the others developed columnar/petal layer with little barrier and/or porous layer. Such varied morphology may be related to local lithium concentration and local $\mathrm{pH}$. High lithium concentration and high $\mathrm{pH}$ may result in the formation of mainly columnar/petal morphology. Adjacent to the primer coating, where relatively high concentration of lithium species is expected, a significant development of the columnar/petal morphology was observed.
In the center of the scribed area, the pathway for leaching is increased and the concentration of lithium species may be relatively low, consequently, barrier-type morphology was formed. On the other hand, the film morphology at local regions may be altered due to the redistribution of the lithium species by the stream of the salt sprayed to the sample surface, or by the variation of local $\mathrm{pH}$ due to local anodic and cathodic activities associated with the different phases in the alloy or the individual grains. The grains with relatively high stored energy might display more anodic activities than that of grains associated with relatively low stored energy. ${ }^{54,55}$ A schematic diagram of the various film morphologies is illustrated in Fig. 12, categorizing five main types of the morphologies observed at different locations in the scribed area. These include high columnar/petal layer with little barrier and porous layers, significant columnar/petal layer with the presence of porous and barrier layers, significant presence of three layered morphology, porous and barrier layers, and barrier layer. Protrusion of the film can be correlated to the scribing-introduced partial delamination of the alloy, the presence of a second phase particle beneath the film, or the presence of the metal debris. The TEM image of the cross section of the alloy substrate in the scribed area revealed the presence of a near-surface deformed layer of about 0.8 to $1 \mu \mathrm{m}$ thickness, as shown in Fig. 7a. The presence or absence of the near surface deformed layer provides a handy tracer to measure the consumption of the alloy during corrosion and filming in the scribed area. In Fig. 8c, a substantial deformed layer of $0.9 \mu \mathrm{m}$ thickness was still present, suggesting that the consumption of the alloy due to the initial corrosion or filming was very limited.

EIS measurements after salt spray exposure confirmed that the presence of lithium carbonate in the primer coating results in the formation of a protective film in the scribed area. Such film formed a physical barrier, resulting in a considerable increase in the values of low-frequency impedance.

\section{Conclusions}

(1) During salt spray exposure of the AA2024 aluminum alloy coated with a lithium carbonate pigmented primer, lithium species were able to leach out from the primer and to migrate to the damaged area. The leached lithium species reacted with aluminum hydroxide 
and formed a film of about 0.2 to $1.5 \mu \mathrm{m}$ thickness on the alloy surface within the damaged area. The morphology of the film varied, with the regions close to the primer coating showing a significant outer columnar/petal layer, and the central region of the scribed area exhibiting mainly a barrier film. The variation of the morphology of the film might be associated with the local concentration of the leached lithium species.

(2) The film is a mixture of amorphous and nano-sized crystalline materials. The lattice fringe images of the nano-crystals suggest that $\mathrm{Li}_{2} \mathrm{Al}_{4} \mathrm{CO}_{3}(\mathrm{OH})_{12} \cdot 3 \mathrm{H}_{2} \mathrm{O}$ and/or $\alpha-\mathrm{LiAlO}_{2}$ and/or $\mathrm{Al}(\mathrm{OH})_{3}$ are present in the film.

(3) The film formed in the damaged area was able to effectively protect the AA2024 aluminum alloy from corrosion during neutral salt spray exposure. Beneath the film, the presence of the near-surface deformed layer of approximately $0.8-1 \mu \mathrm{m}$ thickness, introduced by scribing, indicates a fast and effective inhibition by the leaching lithium species.

(4) Electrochemical impedance spectroscopy showed that such film can form a physical barrier between the bare metal and the aggressive environment, as evident from the presence of an additional time constant and the increase in the impedance at low and medium frequencies.

\section{Acknowledgment}

The authors thank AkzoNobel for sponsoring this work.

\section{References}

1. A. E. Hughes, R. J. Taylor, K. J. H. Nelson, B. R. W. Hinton, and L. Wilson, Materials Science and Technology, 12, 928 (1996).

2. Y. Liu, P. Skeldon, G. E. Thompson, H. Habazaki, and K. Shimizu, Corrosion Science, 47, 341 (2005).

3. D. Chidambaram, C. R. Clayton, G. P. Halada, and M. W. Kendig, Journal of the Electrochemical Society, 151, B605 (2004).

4. S. J. Garcia-Vergara, P. Skeldon, G. E. Thompson, and H. Habazaki, Surf. Interface Anal., 39, 860 (2007).

5. F. H. Scholes, S. A. Furman, A. E. Hughes, and T. A. Markley, Corrosion Science, 48, 1812 (2006).

6. S. A. Furman, F. H. Scholes, A. E. Hughes, D. N. Jamieson, C. M. Macrae, and A. M. Glenn, Corrosion Science, 48, 1827 (2006)

7. S. Sellaiyan, A. E. Hughes, S. V. Smith, A. Uedono, J. Sullivan, and S. Buckman, Progress in Organic Coatings, 77, 257 (2014).

8. E. Akiyama, A. J. Markworth, J. K. McCoy, G. S. Frankel, L. Xia, and R. L. McCreery, Journal of The Electrochemical Society, 150, B83 (2003).

9. S. Huang, B. Peng, Z. Yang, L. Chai, and L. Zhou, Trans. Nonferrous Met. Soc. China, 19, 241 (2009).

10. H. Xie, S. S. Wise, A. L. Holmesa, B. Xu, T. P. Wakemand, S. C. Pelsue, N. P. Singh, and J. P. Wise Sr, Mutation Research, 586, 160 (2005)

11. I. A. Kartsonakis, E. Athanasopoulou, D. Snihirova, B. Martins, M. A. Koklioti, M. F. Montemor, G. Kordas, and C. A. Charitidis, Corrosion Science, 85, 147 (2014).

12. J. S. Warner and R. P. Gangloff, Corrosion Science, 62, 11 (2012).

13. B. del Amo, R. Romagnoli, C. Deyá, and J. A. González, Progress in Organic Coatings, 45, 389 (2002).

14. O. Lopez-Garrity and G. S. Frankel, Electrochimica Acta, 130, 9 (2014).

15. M. Iannuzzi, T. Young, and G. S. Frankel, Journal of The Electrochemical Society, 153, B533 (2006)

16. M. B. Jensen, M. J. Peterson, N. Jadhav, and V. J. Gelling, Progress in Organic Coatings, 77, 2116 (2014)

17. Z. Zou, N. Li, D. Li, H. Liu, and S. Mu, Journal of Alloys and Compounds, 509, 503 (2011).

18. A. E. Hughes, J. D. Gorman, T. G. Harvey, A. Galassi, and G. McAdam, Corrosion, 62, 774 (2006).

19. M. Mohammadi, A. Yazdani, M. E. Bahrololoom, and A. Alfantazi, J. Coat. Technol. Res. 10, 219 (2013).

20. J. Hill, T. Markley, M. Forsyth, P. C. Howlett, and B. R. W. Hinton, Journal of Alloys and Compounds, 509, 1683 (2011)

21. A. Kolics, P. Waszczuk, L. Gáncs, Z. Németh, and A. Wieckowskia, Electrochemical and Solid-State Letters, 3, 369 (2000).

22. T. Stimpfling, F. Leroux, and H. Hintze-Bruening, Eur. J. Inorg. Chem., 5396 (2012).
23. R. Naderi and M. M. Attar, Electrochimica Acta 53, 5692 (2008).

24. S. Mehraban, J. Sullivan, and J. Elvins, ECS Transactions, 50, 377 (2013).

25. R. Tamilarasan and A. Sreekanth, RSC Adv., 3, 23681 (2013).

26. K. Na and S. Pyun, Journal of the Electrochemical Society, 154, C355 (2007).

27. S. J. Garcia, T. Markley, J. M. C. Mol, and A. E. Hughes, Corrosion Science, 69, 346 (2013).

28. T. H. Muster, H. Sullivan, D. Lau, D. L. J. Alexander, N. Sherman, S. J. Garcia T. G. Harvey, T. A. Markley, A. E. Hughes, P. A. Corrigan, A. M. Glenn, P. A. White, S. G. Hardin, J. Mardel, and J. M. C. Mol, Electrochimica Acta, 67, 95 (2012).

29. A. E. Hughes, T. A. Markley, S. J. Garcia, and J. M. C. Mol., Corrosion Engineering, Science and Technology, 49(B), 674 (2014).

30. T. H. Muster, D. Lau, H. Wrubel, N. Sherman, A. E. Hughes, T. G. Harvey, T. Markley, D. L. J. Alexander, P. A. Corrigan, P. A. White, S. G. Hardin, M. A. Glenn, J. Mardel, S. J. Garcia, and J. M. C. Mol, Surface and Interface Analysis, 42, 170 (2010)

31. M. Forsyth, M. Seter, M. Y. Tan, and B. Hinton, Corrosion Engineering, Science and Technology, 49, 130 (2014).

32. M. van Soestbergen, V. Baukh, S. J. F. Erich, H. P. Huinink, and O. C. G. Adan, Progress in Organic Coatings, 77, 1562 (2014)

33. J. Carneiro, J. Tedim, S. C. M. Fernandes, C. S. R. Freire, A. J. D. Silvestre, A. Gandini, M. G. S. Ferreira, and M. L. Zheludkevich, Progress in Organic Coatings, 75, 8 (2012).

34. M. Forsyth, C. M. Forsyth, K. Wilson, T. Behrsing, and G. B. Deacon, Corrosion Science, 44, 2651 (2002)

35. T. A. Markley, J. I. Mardel, A. E. Hughes, B. R. W. Hinton, A. M. Glenn, and M. Forsyth, Materials and Corrosion, 62, 836 (2011)

36. B. Chico, J. Simancas, J. M. Vega, N. Granizo, I. D'1az, D. de la Fuente, and M. Morcillo, Progress in Organic Coatings, 61, 283 (2008).

37. L. W. Wasconcelos, I. C. P. Margarit, O. R. Mattos, F. L. Fragata, and A. S. B. Sombra, Corrosion Science, 43, 2291 (2001).

38. G. Bierwagen, R. Brown, D. Battocchi, and S. Hayes, DoD Corrosion conference $\mathbf{1}$, (2009).

39. G. Bierwagen, R. Brown, D. Battocchi, and S. Hayes, Progress in Organic Coatings, 68, 48 (2010).

40. P. Plagemann, J. Weise, and A. Zockoll, Progress in Organic Coatings, 76, 616 (2013).

41. A. Zockoll, J. Weise, and P. Plagemann, SAE Technical Paper, 1, 2741 (2011).

42. G. Williams, A. J. Coleman, and H. N. McMurray, Electrochimica Acta, 55, 5947 (2010).

43. S. Li, H Zhang, and J. Liu, Trans. Nonferrous Met. Soc. China, 17, 318 (2007).

44. M. L. Zheludkevich, K. A. Yasakau, S. K. Poznyak, and M. G. S. Ferreira, Corrosion Science, 47, 3368 (2005).

45. S. V. Lamaka, M. L. Zheludkevich, K. A. Yasakau, M. F. Montemorb, and M. G. S. Ferreira, Electrochimica Acta, 52, 7231 (2007).

46. A. Seth, W. J. van Ooij, P. Puomi, Z. Yin, A. Ashirgade, S. Bafna, and C. Shivane, Novel, Progress in Organic Coatings, 58, 136 (2007).

47. J. Gui and T. M. Devine, Scripta Metallurgica, 21, 853 (1987).

48. R. G. Buchheit, M. D. Bode, and G. E. Stoner, Corrosion, 50, 206 (1994)

49. C. A. Drewien, M. O. Eatough, D. R. Tallant, C. R. Hills, and R. G. Buchheit, J Mater. Res. 11, 1507 (1996).

50. C. M. Rangel and M. A. Travassos, Surface \& Coatings Technology, 200, 5823 (2006).

51. C. M. Rangel and M. A. Travassos, Corrosion Science, 33, 327 (1992).

52. P. Visser and S. A. Hayes, patent WO 2010112605 A1.

53. P. Visser, Y. Liu, X. Zhou, T. Hashimoto, G. E. Thompson, S. B. Lyon, L. G. J. van der Ven, A. J. M. C. Mol, and H. A. Terryn, Faraday Discussions, 180 $511(2015)$.

54. C. Luo, X. Zhou, G. E. Thompson, and A. E. Hughes, Corrosion Science, 61, 35 (2012).

55. A. E. Hughes, A. Boag, A. M. Glenn, D. McCulloch, T. H. Muster, C. Ryan, C. Luo, X. Zhou, and G. E. Thompson, Corrosion Science, 53, 27 (2012).

56. Y. Liu, X. Zhou, G. E. Thompson, T. Hashimoto, G. M. Scamans, and A. Afseth, Acta Materialia, 55, 353 (2007)

57. X. Zhou, Y. Liu, G. E. Thompson, G. M. Scamans, P. Skeldon, and J. A. Hunter, Metallurgical and Materials Transactions A, 42A, 1373 (2011).

58. Z. Zhao and G. S. Frankel, Corrosion Science, 49, 3064 (2007).

59. Y. Liu, A. Laurino, T. Hashimoto, X. Zhou, P. Skeldon, G. E. Thompson, G. M. Scamans, C. Blanc, W. M. Rainforth, and M. F. Frolish, Surf. Interface Anal. 42, 185 (2010).

60. Y. Liu, T. Hashimoto, X. Zhou, G. E. Thompson, G. M. Scamans, W. M. Rainforth, and J. A. Hunterd, Surf. Interface Anal., 45, 1553 (2013).

61. M. Marezio and J. P. Remeika, The Journal of Chemical Physics, 44, 3143 (1966).

62. K. R. Poeppelmeier, C. K. Chiang, and D. O. Kipp, Inorg. Chem., 27, 4523 (1988).

63. V. P. Isupov, Journal of Structural Chemistry, 40, 672 (1999).

64. H. Saalfeld and M. Wedde,Z. Kristallogr., Kristallgeom., Kristallphys., Kristallchem., 139, 129 (1974)

65. G. Yamaguchi and K. Sakamoto, Bull. Chem. Soc. Jpn., 31, 140 (1958), 